\title{
Exploring the Optimal Range of Central Venous Pressure in Sepsis and Septic Shock Patients: A Retrospective Study in 208 Hospitals
}

\section{Xiaodong Song}

Department of Critical Care Medicine, The First Affiliated Hospital of Sun Yat-Sen University

\section{Zhaoxia Tang}

Department of Critical Care Medicine, The First Affiliated Hospital of Sun Yat-Sen University

\section{Shuhe Li}

Department of Critical Care Medicine, The First Affiliated Hospital of Sun Yat-Sen University

\section{Jinghong Xu}

Department of Critical Care Medicine, The First Affiliated Hospital of Sun Yat-Sen University

\section{Fa Huang}

Department of Critical Care Medicine, The First Affiliated Hospital of Sun Yat-sen University

\section{Xiaoguang Hu}

Department of Critical Care Medicine, The First Affiliated Hospital of Sun Yat-Sen University

\section{Li Tong}

Department of Critical Care Medicine, The First Affiliated Hospital of Sun Yat-Sen University

\section{Lu Cao}

Department of Extracorporeal Circulation, The First Affiliated Hospital of Sun Yat-Sen University

\section{Yanping Zhu}

Department of Critical Care Medicine, The First Affiliated Hospital of Sun Yat-Sen University Jiyou Yao

Department of Hepatobiliary Surgery, Guangzhou First People's Hospital

\section{Xiaobin Lin}

Department of Pharmacology, The First Affiliated Hospital of Sun Yat-Sen University

\section{Xiangdong Guan}

Department of Critical Care Medicine, The First Affiliated Hospital of Sun Yat-Sen University

\section{Ka Yin Lui}

Department of Critical Care Medicine, The First Affiliated Hospital of Sun Yat-Sen University

Changjie Cai ( $\nabla$ caichjie@mail.sysu.edu.cn )

Department of Critical Care Medicine, The First Affiliated Hospital of Sun Yat-Sen University https://orcid.org/0000-0002-0096-1982 
Keywords: Central venous pressure, big-data research, intensive care unit, sepsis, septic shock

Posted Date: August 17th, 2020

DOI: https://doi.org/10.21203/rs.3.rs-56716/v1

License: (c) (1) This work is licensed under a Creative Commons Attribution 4.0 International License. Read Full License 


\section{Abstract}

Background: The appropriate range of central venous pressure (CVP) in sepsis patients remains controversial. The aim of this study was to investigate the optimal CVP range in sepsis and septic shock patients admitted to intensive care unit.

Methods: We performed a retrospective study with adult sepsis patients with CVP records based on the elCU Collaborative Research Database. Cases were divided into three groups according to mean CVP level during ICU stay: low $(<8 \mathrm{mmHg})$, normal $(8-12 \mathrm{mmHg})$, and high $(>12 \mathrm{mmHg})$. Baseline characteristics and clinical outcomes of three groups were compared. Multivariable logistic regression was used to assess the relationship between different CVP levels (by equal interval of $4 \mathrm{mmHg}$ ) and in-hospital death risk.

Results: 5302 sepsis patients were included in this study. Lactate level, serum creatinine, proportion of mechanical ventilation and dialysis were significantly higher in high CVP group compared to normal CVP group $(2.6[1.6,3.4]$ vs $2.2[1.4,2.9] \mathrm{mmol} / \mathrm{L} ; 1.5[1,2.4]$ vs $1.2[0.8,2] \mathrm{mg} / \mathrm{dL} ; 52.2 \%$ vs $48.2 \% ; 14.6 \%$ vs $9.7 \% ; p<0.05$, respectively). In addition, high CVP group tended to have higher ICU mortality ( $24.8 \%$ vs $15.9 \%, p<0.05)$ and hospital mortality $(32.2 \%$ vs $22.4 \%, p<0.05)$. The logistic regression analyses revealed that, in sepsis patients, CVP range of $12-16 \mathrm{mmHg}, 16-20 \mathrm{mmHg}$ and $>20 \mathrm{mmHg}$ was related to increased in-hospital death risk compared to $8-12 \mathrm{mmHg}$ level (OR: 1.349, 2.287, 3.210, respectively; $95 \%$ Cl: $1.161-1.568,1.897-2.757,2.403-4.290$, respectively); there were no significant differences between 0-4 mmHg, 4-8 mmHg and 8-12 mmHg levels regarding in-hospital death risk. Whereas in septic shock patients, CVP level of $0-4 \mathrm{mmHg}, 12-16 \mathrm{mmHg}, 16-20 \mathrm{mmHg}$ and $>20 \mathrm{mmHg}$ all contributed to increased in-hospital death risk (OR: 1.914, 1.652, 3.305, 3.554, respectively; 95\% Cl: 1.165-3.146, 1.299-2.101, $2.444-4.47,2.233-5.654$, respectively).

Conclusions: High CVP level (> $12 \mathrm{mmHg}$ ) was related to worse clinical outcomes in both sepsis and septic shock patients; while very low CVP level $(<4 \mathrm{mmHg})$ in septic shock patients was also harmful. More strict fluid administration was essential in septic shock population.

\section{Background}

Central venous pressure (CVP) is frequently measured to monitor the circulatory status of critically ill patients. As a widely used hemodynamic index, achieving a CVP $>8 \mathrm{mmHg}$ is considered standard policy during fluid resuscitation (Early Goal Directed Therapy, EGDT)[1, 2]. CVP is influenced by venous return and cardiac function[3, 4]. High CVP will impede venous return to the heart in turn, which may disturb microcirculatory perfusion[5], damage organ function and increase mortality: A single center retrospective study showed that critically ill patients with a peak CVP $>12 \mathrm{mmHg}$ were associated with prolonged ICU stay and worse organ function[6]. A meta-analysis also revealed that elevated CVP is associated with an increased risk of mortality and acute kidney injury in critically ill adult patients (mainly sepsis)[7].

Meanwhile, several studies also demonstrate that low CVP level may improve clinical outcomes. In septic 
shock patients, a single center study found that patients whose CVP dropped to less than $8 \mathrm{mmHg}$ during 7 days had survival advantage[8]. Another multicenter retrospective research enrolling 778 septic shock patients also revealed that patients with $\mathrm{CVP}<8 \mathrm{mmHg}$ had lowest mortality rate at 12 hours after ICU admissions[9]. The phenomenon elevated CVP was linked to poor clinical outcomes had caught the attention of clinical staff, nevertheless the appropriate CVP ranges in critically ill patients are still up in the air and it seemed that the association between CVP and clinical outcomes differed in subgroups.

What is the optimal CVP range in sepsis patients? Would it be different in septic shock population? In this study, we aimed to assess the association between mean CVP level and clinical outcomes in sepsis and septic shock patients, utilizing the real-world data obtained from the multi-center database for critical care research (the eICU Collaborative Research Database).

\section{Methods}

\section{Database}

We employed the elCU Collaborative Research Database for this study. The eICU database is a freely available multi-center database for critical care research with high granularity data monitored by elCU Programs for over 200,000 admissions to ICUs from 208 hospitals across the United States. After completing the Collaborative Institutional Training Initiative training course "Data or Specimens Only Research", we have obtained approval to access the database. The up-to-date version 2.0 of elCU database was used[10].

\section{Study Population And Data Extraction}

All patients in the database were screened. The following inclusion criteria were applied: (1) age above 18 years; (2) meet the diagnosis of "sepsis"; (3) at least one CVP record during ICU stay.

Data on the following aspects were extracted: age, gender, Acute Physiology and Chronic Health Evaluation IV (Apache IV), ethnicity, admission ICU type, sepsis classification, comorbidities (hypertension, diabetes, chronic kidney disease (CKD), chronic obstructive pulmonary disease (COPD), heart failure, cancer, and septic shock), interventions (ventilation, dialysis, vasopressor, and antibiotics), vital laboratory test (white blood cell count, hemoglobin, platelets, glucose, lactate, blood urea nitrogen (BUN), serum creatinine (Scr), alanine aminotransferase (ALT), and aspartate transaminase (AST)), ICU length of stay (LOS), hospital LOS, ICU mortality, and hospital mortality. The database had obscured the true ages of patients over 89 years old. The median age of those patients was 91.5 years, and we used this value as a surrogate age for those patients. According to our clinical experience, a CVP value above $25 \mathrm{mmHg}$ was considered as an invalid measurement and was excluded in the procedure of data extraction. Data extraction was accomplished using structure query language (SQL) by PostgreSQL tools (v12.1; PostgreSQL Global Development Group). 


\section{Exposure And Outcomes}

The primary exposure in our research was the mean CVP level during ICU stay. We set the normal CVP range at 8-12 mmHg according to the description of Surviving Sepsis Campaign 2016[11]. The primary outcomes were the hospital mortality. The secondary outcomes included in-ICU mortality, ICU LOS, hospital LOS, demands for mechanical ventilation/dialysis/vasopressors and laboratory results related to organ dysfunction.

\section{Statistical analysis}

Numeration variables were expressed as absolute values and percentages; the Pearson chi-square test was used for comparisons between groups. Continuous variables are expressed as mean \pm SD (standard deviation) for normally distributed data or median [interquartile range (IQR)] for non-normally distributed data. Continuous variables were compared using $t$ test or one-way analysis of variance for normally distributed quantitative data, and Wilcoxon rank-sum test or Mann-Whitney U test for non-normally distributed quantitative data to determine differences between groups.

Kaplan-Meier survival curves of 30-day survival probability were generated with the log-rank test to determine whether survival probability differs in different mean CVP group.

Univariate analysis was carried out between survivors and non-survivors to screen variables associated with hospital mortality by Pearson chi-square test. The variables with $\mathrm{P}<0.2$ in the univariate analysis were included in the logistic regression model as covariates to determine the factors that impact the hospital mortality.

SPSS (version 22.0; IBM, Armonk, NY) and R (version 3.6.3, R Foundation for Statistical Computing, Vienna, Austria; https://www.R-project.org/) were used for statistical analyses. A two-tailed $\mathrm{P}<0.05$ was considered statistically significant.

\section{Results}

\section{Population and baseline characteristics}

As shown in Fig. 1, we extracted 5307 admissions diagnosed as "sepsis" with CVP record during ICU stay, of whom there were 5 patients aged less than 18 years. At last we included 5302 admissions for 5057 unique patients in our study population.

We stratified patients into three groups according to mean CVP level during ICU stay: low CVP group: CVP $\leq 8 \mathrm{mmHg}$; normal CVP group: $8 \mathrm{mmHg}<$ CVP $\leq 12 \mathrm{mmHg}$; high CVP group: CVP > $12 \mathrm{mmHg}$. Results of the baseline characteristics of 5307 septic patients are summarized in Table 1. Compared to patients in normal CVP group, patients in high CVP group tended to be younger, owning larger proportion of CKD, COPD and heart failure and required greater demands for ventilation and dialysis. Compare to patients in 
low CVP group, patients in high CVP group were associated with higher APACHE IV score, larger proportion of CKD/COPD/heart failure/septic shock and greater demands for ventilation/dialysis/vasopressor. Patients in normal CVP group were associated with younger year and greater demands for ventilation/dialysis compared to patients in low CVP group. 
Table 1

Baseline characteristics of sepsis patients stratified by mean CVP level during ICU stay.

\begin{tabular}{|c|c|c|c|c|}
\hline Variables & $\begin{array}{l}\text { Low CVP } \\
\leq 8 \mathrm{mmHg}\end{array}$ & $\begin{array}{l}\text { Normal CVP } \\
(8 \sim 12] \mathrm{mmHg}\end{array}$ & $\begin{array}{l}\text { High CVP } \\
>12 \mathrm{mmHg}\end{array}$ & $\mathbf{P}$ \\
\hline No. of patients & 1423 & 1894 & 1985 & \\
\hline Age & $70(58,80)^{a}$ & $67(56,77)^{\mathrm{b}}$ & $65(56,76)^{c}$ & $<0.001$ \\
\hline Gender (male), n (\%) & $771(54.2)^{a}$ & $920(48.6)^{b}$ & $978(49.3)^{b}$ & 0.003 \\
\hline Apache IV & $72(57,90)^{a}$ & $75(57,95)^{a, b}$ & $76(60,96)^{b}$ & $<0.001$ \\
\hline ICU type, n (\%) & & & & 0.013 \\
\hline Cardiac ICU & $72(5.1)^{a}$ & $143(7.6)^{b}$ & $135(6.8)^{a, b}$ & \\
\hline CCU-CTICU & $85(6)^{a}$ & $108(5.7)^{a}$ & $132(6.6)^{a}$ & \\
\hline CSICU & $23(1.6)^{a}$ & $24(1.3)^{\mathrm{a}}$ & $39(2)^{\mathrm{a}}$ & \\
\hline CTICU & $11(0.8)^{\mathrm{a}}$ & $20(1.1)^{\mathrm{a}}$ & $10(0.5)^{a}$ & \\
\hline Med-Surg ICU & $952(66.9)$ & $1255(66.3)$ & $1316(66.3)$ & \\
\hline MICU & $213(15)^{\mathrm{a}}$ & $240(12.7)^{a}$ & $256(12.9)^{a}$ & \\
\hline Neuro ICU & $26(1.8)^{a}$ & $21(1.1)^{a}$ & $24(1.2)^{\mathrm{a}}$ & \\
\hline SICU & $41(2.9)^{\mathrm{a}}$ & $83(4.4)^{\mathrm{a}}$ & $73(3.7)^{a}$ & \\
\hline Sepsis, n (\%) & & & & $<0.001$ \\
\hline Cutaneous/soft tissue & $73(5.1)^{\mathrm{a}}$ & $121(6.4)^{\mathrm{a}}$ & $191(9.6)^{b}$ & \\
\hline Gastrointestinal & $217(15.2)^{a}$ & $319(16.8)^{a}$ & $295(14.9)^{a}$ & \\
\hline Gynecologic & $5(0.4)^{\mathrm{a}}$ & $6(0.3)^{a}$ & $5(0.3)^{a}$ & \\
\hline Pulmonary & $545(38.3)^{\mathrm{a}}$ & $725(38.3)^{\mathrm{a}}$ & $782(39.4)^{a}$ & \\
\hline Renal/UTI & $345(24.2)^{a}$ & $427(22.5)^{a, b}$ & $386(19.4)^{b}$ & \\
\hline Other/unknown & $238(16.7)^{a}$ & $296(15.6)^{a}$ & $326(16.4)^{a}$ & \\
\hline \multicolumn{5}{|l|}{ Comorbidities, n (\%) } \\
\hline Hypertension & $104(7.3)^{\mathrm{a}}$ & $116(6.1)^{\mathrm{a}}$ & $147(7.4)^{\mathrm{a}}$ & 0.232 \\
\hline Diabetes & $190(13.4)^{a, b}$ & $240(12.7)^{b}$ & $322(16.2)^{a}$ & 0.004 \\
\hline
\end{tabular}




\begin{tabular}{|lllll|}
\hline Variables & $\begin{array}{l}\text { Low CVP } \\
\leq 8 ~ \mathbf{~ m H g}\end{array}$ & $\begin{array}{l}\text { Normal CVP } \\
(8 \sim 12] ~ \mathbf{~ m H g}\end{array}$ & $\begin{array}{l}\text { High CVP } \\
>12 ~ \mathbf{~ m H g}\end{array}$ & P \\
\hline CKD & $140(9.8)^{\mathrm{a}}$ & $194(10.2)^{\mathrm{a}}$ & $285(14.4)^{\mathrm{b}}$ & $<0.001$ \\
\hline COPD & $113(7.9)^{\mathrm{a}}$ & $137(7.2)^{\mathrm{a}}$ & $206(10.4)^{\mathrm{b}}$ & 0.001 \\
\hline Heart failure & $95(6.7)^{\mathrm{a}}$ & $138(7.3)^{\mathrm{a}}$ & $224(11.3)^{\mathrm{b}}$ & $<0.001$ \\
\hline Cancer & $76(5.3)^{\mathrm{a}}$ & $91(4.8)^{\mathrm{a}}$ & $105(5.3)^{\mathrm{a}}$ & 0.724 \\
\hline Septic shock & $469(33)^{\mathrm{a}}$ & $687(36.3)^{\mathrm{a}, \mathrm{b}}$ & $758(38.2)^{\mathrm{b}}$ & 0.007 \\
\hline Intervention & & & & \\
\hline Ventilation, $\mathrm{n}(\%)$ & $535(37.6)^{\mathrm{a}}$ & $912(48.2)^{\mathrm{b}}$ & $1037(52.2)^{\mathrm{c}}$ & $<0.001$ \\
\hline Dialysis, $\mathrm{n}(\%)$ & $92(6.5)^{\mathrm{a}}$ & $184(9.7)^{\mathrm{b}}$ & $290(14.6)^{\mathrm{c}}$ & $<0.001$ \\
\hline Vasopressor, $\mathrm{n}(\%)$ & $671(47.2)^{\mathrm{a}}$ & $955(50.4)^{\mathrm{a}, \mathrm{b}}$ & $1058(53.3)^{\mathrm{b}}$ & 0.002 \\
\hline Antibiotics, $\mathrm{n}(\%)$ & $777(54.6)^{\mathrm{a}}$ & $1023(54)^{\mathrm{a}}$ & $1070(53.9)^{\mathrm{a}}$ & 0.914 \\
\hline
\end{tabular}

\section{Clinical Outcomes And Kaplan-meier Survival Analysis}

We showed the main clinical outcomes of the study population in Table 2. Higher mean CVP level was associated with higher level of Scr, ALT and AST. Lactate and BUN level in high CVP group were higher than low CVP group and normal CVP group; there were no statistical significance regarding lactate and BUN level between low CVP group and normal CVP group. Patients in low CVP group owned shortest ICU LOS $(3(1.8,5.8)$ days vs $3.7(2,7.5)$ days vs $3.6(1.8,7)$ days, $p<0.001)$; patients in high CVP group owned shortest Hospital LOS $(8.5(5,14.3)$ days vs $8.6(5,15)$ days vs $8(4.2,14.1)$ days, $p=0.002)$. Higher level of CVP group was associated with higher ICU mortality $(12.1 \%$ vs $15.9 \%$ vs $24.8 \%, P<0.001)$. Patients in high CVP group owned highest hospital mortality (32.2\%); there were no significant difference between low CVP group and normal CVP group regarding hospital mortality $(20.4 \%$ vs $22.4 \%, P>0.05)$. 
Table 2

Clinical outcomes of sepsis patients stratified by mean CVP level during ICU stay.

\begin{tabular}{|c|c|c|c|c|}
\hline Variables & $\begin{array}{l}\text { Low CVP } \\
\leq 8 \mathrm{mmHg}\end{array}$ & $\begin{array}{l}\text { Normal CVP } \\
(8 \sim 12] \mathrm{mmHg}\end{array}$ & $\begin{array}{l}\text { High CVP } \\
>12 \mathrm{mmHg}\end{array}$ & $\mathbf{P}$ \\
\hline Wbc, $\left(10^{9} / \mathrm{L}\right)$ & $12(8.8,16.1)^{\mathrm{a}}$ & $12.5(9.3,16.4)^{a, b}$ & $13(9.3,17.1)^{b}$ & 0.001 \\
\hline Hemoglobin, (g/dL) & $9.8(8.8,11)^{\mathrm{a}}$ & $9.8(8.8,11.1)^{a}$ & $9.8(8.8,11.2)^{a}$ & 0.586 \\
\hline Platelets, (K/uL) & $\begin{array}{l}192.7(135.6 \\
260.6)^{a}\end{array}$ & $188(126.1,252.9)^{a}$ & $\begin{array}{l}173.7(114.2, \\
238.2)^{\mathrm{b}}\end{array}$ & $<.001$ \\
\hline Glucose, (mg/dL) & $\begin{array}{l}127.2(107.3 \\
153.1)^{\mathrm{a}}\end{array}$ & $\begin{array}{l}130.3(110.6 \\
157.9)^{\mathrm{b}}\end{array}$ & $\begin{array}{l}133.4(112.5 \\
161.9)^{\mathrm{b}}\end{array}$ & $<.001$ \\
\hline Lactate, (mmol/L) & $2.2(1.4,2.7)^{a}$ & $2.2(1.4,2.9)^{\mathrm{a}}$ & $2.6(1.6,3.4)^{\mathrm{b}}$ & $<.001$ \\
\hline BUN, (mg/dL) & $25.5(16,41.5)^{\mathrm{a}}$ & $27.6(17.2,42.3)^{a}$ & $31.8(20.7,46.5)^{b}$ & $<.001$ \\
\hline $\mathrm{Scr},(\mathrm{mg} / \mathrm{dL})$ & $1.1(0.8,1.8)^{a}$ & $1.2(0.8,2)^{b}$ & $1.5(1,2.4)^{\mathrm{c}}$ & $<.001$ \\
\hline ALT, (U/L) & $28(17,57.5)^{a}$ & $32(19,74.5)^{\mathrm{b}}$ & $39.2(22,81.6)^{\mathrm{c}}$ & $<.001$ \\
\hline AST, (U/L) & $33(20,70.2)^{a}$ & $40.4(23,99)^{\mathrm{b}}$ & $51(27.9,122.5)^{\mathrm{C}}$ & $<.001$ \\
\hline ICU LOS, (day) & $3(1.8,5.8)^{a}$ & $3.7(2,7.5)^{b}$ & $3.6(1.8,7)^{b}$ & $<.001$ \\
\hline Hospital LOS, (day) & $8.5(5,14.3)^{a}$ & $8.6(5,15)^{a}$ & $8(4.2,14.1)^{b}$ & 0.002 \\
\hline ICU mortality, n (\%) & $172(12.1)^{a}$ & $301(15.9)^{b}$ & $493(24.8)^{\mathrm{c}}$ & $<.001$ \\
\hline $\begin{array}{l}\text { Hospital mortality, n } \\
(\%)\end{array}$ & $290(20.4)^{a}$ & $425(22.4)^{a}$ & $640(32.2)^{b}$ & $\begin{array}{l}< \\
0.001\end{array}$ \\
\hline \multicolumn{5}{|c|}{$\begin{array}{l}\text { Abbreviations: CVP: central venous pressure, ICU intensive care unit, WBC: white blood cell count, } \\
\text { BUN: blood urea nitrogen, Scr: serum creatinine, ALT: alanine aminotransferase, AST: aspartate } \\
\text { transaminase, LOS: length of stay. }\end{array}$} \\
\hline
\end{tabular}

a b c: There is statistical difference in target variable between groups with the different superscript letters at the 0.05 level.

Kaplan-Meier survival curves of 30-day survival probability are shown in Fig. 2. Notable survival advantage in low CVP group and normal CVP group existed compared with high CVP group $(p<0.001$, respectively). While there was no significant difference between low CVP group and normal CVP group ( $P$ $=0.238$ ). 
Considering that there were no statistical differences between low CVP group and normal CVP group in hospital mortality and Kaplan-Meier survival curves of 30-day survival probability. We divided CVP level into more detailed groups by equal interval of $4 \mathrm{mmHg}: 0-4 \mathrm{mmHg}, 4-8 \mathrm{mmHg}, 8-12 \mathrm{mmHg}$ (normal CVP range), $12-16 \mathrm{mmHg}, 16-20 \mathrm{mmHg}$ and $>20 \mathrm{mmHg}$. As Fig. 3 showed, $4-8 \mathrm{mmHg}$ group owned the lowest hospital mortality (19.7\%), though no statistical difference existed between $0-4 \mathrm{mmHg}$ group and $8-12 \mathrm{mmHg}$ group ( $24.5 \%$ vs $22.4 \%, \mathrm{P}<0.05$ ), and between $4-8 \mathrm{mmHg}$ group and $8-12 \mathrm{mmHg}$ group ( $19.7 \%$ vs $22.4 \%, \mathrm{P}<0.05)$. Mortalities of the other 3 groups all exceeded $8-12 \mathrm{mmHg}$ group with statistical differences $(27.4 \%$ vs $22.4 \%, 39 \%$ vs $22.4 \%, 45.2 \%$ vs $22.4 \%$; $\mathrm{P}<0.05$, respectively).

\section{Logistic Regression Analyses Of Hospital Mortality In Sepsis Patients}

After comparing the variables between hospital survivors and non-survivors in the univariate analysis (see Supplemental Table 1), we chose age, gender, APACHE IV score, sepsis classification, Comorbidities (hypertension, diabetes, CKD, heart failure, cancer and septic shock), interventions (ventilation, dialysis,

vasopressor and antibiotics) and groups of mean CVP level into the logistic regression model. In order to study the association between hospital mortality and mean CVP level, we used CVP groups by equal interval of $4 \mathrm{mmHg}$.

Our multivariate regression model revealed relations between CVP and hospital mortality (see Fig. 4): in case CVP level of $8-12 \mathrm{mmHg}$ as reference (normal CVP range), when mean CVP level exceeds $12 \mathrm{mmHg}$, the odds ratio of hospital mortality increased with it: in-hospital death risk in 12-16 mmHg level was 0.349 -times higher than the $8-12 \mathrm{mmHg}$ level (OR 1.349, 95\% Cl 1.161-1.568, $\mathrm{P}=0.001)$; inhospital death risk in 16-20 mmHg level was 1.287-times higher than $8-12 \mathrm{mmHg}$ level (OR 2.287, 95\% $\mathrm{Cl} 1.897-2.757, \mathrm{P}<0.001$ ); in-hospital death risk in $>20 \mathrm{mmHg}$ level was 2.21-times higher than 8$12 \mathrm{mmHg}$ level (OR 3.210,95\% Cl 2.403-4.290, $\mathrm{P}<0.001)$. While there were no significant differences between $0-4 \mathrm{mmHg}, 4-8 \mathrm{mmHg}$ and $8-12 \mathrm{mmHg}$ levels regarding in-hospital death risk $(P=0.143, P=$ 0.353 , respectively). Generally, elder age or higher Apache IV score were related to increased death risk (OR 1.022, 95\% Cl 1.018-1.026; OR 1.021, 95\% Cl 1.018-1.023; $\mathrm{P}<0.001$, respectively). Mechanical ventilation, dialysis, use of vasopressor and comorbidity of cancer were correlated with increased death risk (OR 1.636, 95\% Cl 1.434-1.868, P<0.001; OR 1.263, 95\% Cl 1.056-1.511, P = 0.032; OR 1.369, 95\% Cl $1.205-1.555, \mathrm{P}<0.001)$. Use of antibiotics were correlated with decreased death risk (OR $0.715,95 \% \mathrm{Cl}$ $0.636-0.805, \mathrm{P}<0.001)$.

Clinical outcomes and logistic regression analyses of hospital mortality in sepsis patients with/without septic shock

In order to explore the association between different mean CVP level with clinical outcomes in sepsis patients with/without septic shock. We divided 5302 patients into septic shock population $(n=1914)$ and 
non-septic-shock population $(n=3388)$ according to whether these patients underwent septic shock during hospitalization.

Supplemental Table 2 showed the clinical outcomes in septic shock patients. Similar to sepsis population, higher CVP level was associated with higher level of Lactate, BUN, Scr, ALT, AST. Patients in high CVP group owned highest ICU and hospital mortality (30.7\% and $39.3 \%$, respectively); there were no significant difference between low CVP group and normal CVP group regarding ICU and hospital mortality ( $17.5 \%$ vs $17 \%$ for ICU mortality; $26 \%$ vs $23.3 \%$ for hospital mortality; $P>0.05$, respectively). Clinical outcomes in non-septic-shock patients (see Supplemental Table 3) also revealed the association between higher CVP level and higher level of Lactate, BUN, Scr, ALT, AST in non-septic-shock patients. ICU and hospital mortality increased with the mean CVP level gradually ( $9.4 \%$ vs $15.2 \%$ vs $21.2 \%$ for ICU mortality; $17.6 \%$ vs $22 \%$ vs $27.9 \%$ for hospital mortality; $P<0.05$, respectively).

Table 3 showed the association between adjusted odds ratio of different mean CVP level and hospital mortality: in septic shock population, there was no significant difference in odds ratio between 4$8 \mathrm{mmHg}$ and $8-12 \mathrm{mmHg}$ levels $(P=0.284)$. While CVP in range of $0-4 \mathrm{mmHg}, 12-16 \mathrm{mmHg}, 16-$ $20 \mathrm{mmHg}$ and $>20 \mathrm{mmHg}$ was associated with increased in-hospital death risk compared to 8$12 \mathrm{mmHg}$ level (OR 1.914, 95\% Cl 1.165-3.146, $\mathrm{P}=0.032$; OR 1.652, 95\% Cl 1.299-2.101, $\mathrm{P}<0.001$; OR $3.305,95 \% \mathrm{Cl} 2.444-4.470, \mathrm{P}<0.001$; OR 3.554, 95\% Cl 2.233-5.654, $\mathrm{P}<0.001)$. In non-septic-shock patients, there were no significant differences in death risk between $4-8 \mathrm{mmHg}$ and $8-12 \mathrm{mmHg}(\mathrm{P}=$ $0.803), 0-4 \mathrm{mmHg}$ and $8-12 \mathrm{mmHg}(P=0.063)$, and $12-16 \mathrm{mmHg}$ and $8-12 \mathrm{mmHg}(P=0.131)$. CVP range of 16-20 mmHg and $>20 \mathrm{mmHg}$ was associated with increased death risk compared to 8$12 \mathrm{mmHg}$ level (OR 1.826, 95\% Cl 1.433-2.328; OR 3.023, 95\% Cl 2.082-4.390; $\mathrm{P}<0.001$, respectively).

Table 3 Association between different CVP level and hospital mortality in sepsis patients with/without septic shock.

a. Septic shock patients

\begin{tabular}{|llll|}
\hline CVP level & Death, $\mathrm{n}(\%)$ & Unadjusted odds ratio & Adjusted odds ratio \\
\hline $0-4 \mathrm{mmHg}$ & $22(30.1 \%)$ & $1.421(0.91-2.217) \mathrm{P}=0.194$ & $1.914(1.165-3.146) \mathrm{P}=0.032$ \\
\hline $4-8 \mathrm{mmHg}$ & $100(25.3 \%)$ & $1.113(0.874-1.416) \mathrm{P}=0.466$ & $1.189(0.912-1.551) \mathrm{P}=0.284$ \\
\hline $8-12 \mathrm{mmHg}$ & $160(23.3 \%)$ & $1.000($ reference $)$ & 1.000 (reference) \\
\hline $12-16 \mathrm{mmHg}$ & $158(33.1 \%)$ & $1.626(1.307-2.023) \mathrm{P}<0.001$ & $1.652(1.299-2.101) \mathrm{P}<0.001$ \\
\hline $16-20 \mathrm{mmHg}$ & $104(49.3 \%)$ & $3.201(2.442-4.197) \mathrm{P}<0.001$ & $3.305(2.444-4.47) \mathrm{P}<0.001$ \\
\hline$>20 \mathrm{mmHg}$ & $36(52.2 \%)$ & $3.593(2.353-5.487) \mathrm{P}<0.001$ & $3.554(2.233-5.654) \mathrm{P}<0.001$ \\
\hline
\end{tabular}

1. b. Non septic shock patients 


\begin{tabular}{|llll|}
\hline CVP level & Death, $\boldsymbol{n}(\%)$ & Unadjusted odds ratio & Adjusted odds ratio \\
\hline $0-4 \mathrm{mmHg}$ & $30(21.6 \%)$ & $0.978(0.684-1.399) \mathrm{P}=0.92$ & $1.061(0.719-1.566) \mathrm{P}=0.803$ \\
\hline $4-8 \mathrm{mmHg}$ & $138(16.9 \%)$ & $0.725(0.598-0.878) \mathrm{P}=0.006$ & $0.793(0.645-0.973) \mathrm{P}=0.063$ \\
\hline $8-12 \mathrm{mmHg}$ & $265(22 \%)$ & $1.000($ reference $)$ & 1.000 (reference) \\
\hline $12-16 \mathrm{mmHg}$ & $185(23.9 \%)$ & $1.118(0.934-1.339) \mathrm{P}=0.306$ & $1.196(0.984-1.454) \mathrm{P}=0.131$ \\
\hline $16-20 \mathrm{mmHg}$ & $113(32.7 \%)$ & $1.724(1.383-2.149) \mathrm{P}<0.001$ & $1.826(1.433-2.328) \mathrm{P}<0.001$ \\
\hline$>20 \mathrm{mmHg}$ & $44(40.7 \%)$ & $2.444(1.736-3.440) \mathrm{P}<0.001$ & $3.023(2.082-4.39) \mathrm{P}<0.001$ \\
\hline
\end{tabular}

\section{Discussion}

In this retrospective analysis based on the real-world data extracted from the multi-center database eICU, we focused on the association between mean CVP level during ICU stay with the clinical outcomes in sepsis population. We found that in sepsis patients, high mean CVP level ( $>12 \mathrm{mmHg}$ ) was related to higher ICU and hospital mortality, higher level of Scr, ALT, AST, lactate and BNU level and greater demands for mechanical ventilation and dialysis, compared with normal CVP range (8-12 $\mathrm{mmHg}$ ). In-hospital death risk increased with mean CVP level when CVP $>12 \mathrm{mmHg}$ in sepsis population; however, in septicshock population, both CVP $<4 \mathrm{mmHg}$ and $\mathrm{CVP}>12 \mathrm{mmHg}$ were related with increased risk of in-hospital death compared with normal CVP range. Thus, our study recommended a mean CVP level not exceeding $12 \mathrm{mmHg}$ in the management of sepsis patients. While a relative narrow CVP range $(4-12 \mathrm{mmHg})$ was recommended in septic shock patients.

CVP is frequently used by clinicians to help determinate the status of circulating blood volume and cardiac function. Is there a safe range of CVP for sepsis and septic shock patients? The Surviving Sepsis Campaign 2012 has recommended achieving a CVP of $8 \mathrm{mmHg}$ in the first $6 \mathrm{~h}$ of resuscitation of sepsisinduced tissue hypoperfusion[2]. Lately in 2014 and 2015, three independent, multicenter, governmentfunded, randomized controlled trials all concluded that no survival benefit of EGDT was found compared to usual resuscitation in severe sepsis and septic shock[12-14]. With increasing evidences demonstrating the ineffectiveness of achieving a CVP of $8 \mathrm{mmHg}$ in the management of sepsis, the Surviving Sepsis Campaign 2016 no longer took this approach into recommendation[11]. In 2015, a retrospective study by Wang XT et al indicated that septic shock patients whose CVP dropped to less than $8 \mathrm{mmHg}$ during 7 days after ICU admission had a higher survival rate[8]. The same study group lately demonstrate in 488 critically ill patients that exposure to higher levels of central venous pressure was associated with a poorer prognosis and worse organ function in 2017[6]. Similar articles describing the worse prognosis accompanied with high CVP level in different subgroups of critically ill population sprang up in recent years. Along with former studies, our research revealed a higher ICU and hospital mortality as well as worse organ function in sepsis patients whose CVP level $>12 \mathrm{mmHg}$, indicating that keeping a relatively low CVP level may be the correct choice in management of sepsis patients. Though CVP performed badly in reflecting blood volume or predicting fluid responsiveness[3, 4, 15], the 
association between elevated CVP with worse clinical outcomes might act as a warning that clinical staff should be cautious to give massive fluid bolus to critically ill patients.

Our study also demonstrated increased in-hospital mortality risk in septic shock patients whose CVP< $4 \mathrm{mmHg}$ compared with those with normal mean CVP level. At first, we divided sepsis patients into three groups by low/normal/high CVP group as former research did in the step of grouping study population. We found no statistical difference in hospital mortality and Kaplan-Meier survival curves of 30-day survival rate between low CVP group and normal CVP group; but hospital mortality in Fig. 3 showed a Ulike tendency when we grouped patients into six groups by equal interval of $4 \mathrm{mmHg}$, with $4-8 \mathrm{mmHg}$ group owning lowest mortality. In the step of logistic regression analysis, therefore, we divided CVP into six levels as above and set $8-12 \mathrm{mmHg}$ level as reference. In our logistic regression model of septic shock patients, we found that both very low $(<4 \mathrm{mmHg})$ or high $(>12 \mathrm{mmHg})$ CVP level were related to increased in-hospital death risk. Former researches exploring the survival advantage of different CVP level tended to divide patients into three groups (low/normal/high). The association of very low CVP level and poor prognosis may be covered up by this kind of grouping method. For example, the study by Dr. Boyd concluded that at 12 hours after ICU admission, patients whose CVP $<8 \mathrm{mmHg}$ had a survival advantage over those with $8-12 \mathrm{mmHg}$ in septic shock patients[9]. It might convey the message that clinical staff should control the CVP level of septic shock patients as low as possible. Maintaining hemodynamic stability should be the first priority in the initial resuscitation phase of septic shock. In patients with high CVP level, fluid perfusion may compromise organ function. If CVP level is very low, an initial moderate fluid bolus is less likely to cause harm[16]. We recommended strict fluid administration in septic shock population to maintain the proper range of CVP at $4-12 \mathrm{mmHg}$ based on our findings.

Our findings were partly consistent to the study based on another critical care database (MIMIC-邓) generally, which included 9090 critically ill patients[17]. They found that higher mean CVP level within 3 days after ICU admission was associated with increased 28-day mortality, prolonged duration of vasopressor treatment and mechanical ventilation, and worse organ dysfunction. Nevertheless, there were some differences between the two studies based on real-world database: first, MIMIC database is a single-center for 46,476 unique critical care patients admitted to ICUs at the Beth Israel Deaconess Medical Centre in the US from 2001 to 2012[18]; while the elCU Collaborative Research Database is a multi-center database with high granularity data for 139,367 unique patients to ICUs between 2014 and 2015 monitored by elCU Programs across the United States[10]. In our opinion, the elCU database had better generalizability owing to the nature of multi-center database. Second, Liu's study focused on the critically ill patients, while we were interested in the specific sepsis and septic shock population. Third, Liu's study demonstrated increased hazard ratio 28-day mortality in groups of higher CVP by quartiles; while our study showed increased odds ratio in-hospital mortality with higher CVP level by equal interval of $4 \mathrm{mmHg}$, and a relatively low level of CVP in septic shock population was also related to increased inhospital death risk. There were differences in study population and statistic methods between the two big-data researches, while both studies conveyed the similar warning that clinical staff should pay attention to high CVP level and its negative impacts on critically ill patients. 
There are some limitations in our study: first, due to the nature of retrospective analysis, no causal relationships could be established from our study. We could conclude that there was association between elevated CVP and wore clinical outcomes. But how to explain this phenomenon needs further research and discussion. Second, the research data came from the public database eICU. We only included patients with CVP records during ICU stay, which caused selective bias virtually. Meanwhile, the CVP value in eICU database consisted of manual records by nurses and automatic records by monitor instruments. We removed measurements of CVP above $25 \mathrm{mmHg}$ and claimed them to ineffective measurements by our clinical experience. This might make contribution to bias, too. To be honest, it's hard to avoid these biases in the process of data extraction and process because of the property of Big Data research.

\section{Conclusions}

In this retrospective multi-center sepsis cohort based on public database, we observed that high CVP level $(>12 \mathrm{mmHg}$ ) was related to worse clinical outcomes in both septic and septic shock patients; while different from septic patients, very low CVP range $(<4 \mathrm{mmHg})$ in septic shock patients was also related to greater risk of death. More strict fluid administration was essential in septic shock patients.

\section{Abbreviations}

CVP

central venous pressure, ICU intensive care unit, Apache IV:Acute Physiology and Chronic Health Evaluation IV, CCU-CTICU:Coronary Care Unit/Cardiothoracic intensive care unit, CSICU:Cardiac Surgery intensive care unit, CTICU:Cardiothoracic intensive care unit, Med-Surg ICU:Medical-Surgical intensive care unit, MICU:Medical intensive care unit, Neuro ICU:Neurological intensive care unit, SICU:Surgical intensive care unit, UTI:urinary tract infection, CKD:Chronic kidney disease, COPD:chronic obstructive pulmonary disease.

a b c

There is statistical difference in target variable between groups with the different superscript letters at the 0.05 level.

\section{Declarations}

\section{Ethics approval and consent to participate}

Raw data in this research came from the elCU Collaborative Research Database, which was released under the Health Insurance Portability and Accountability Act (HIPAA) safe harbor provision. The reidentification risk was certified as meeting safe harbor standards by Privacert (Cambridge, MA) (HIPAA Certification no. 1031219-2). We gained access to the database after completion of the National Institute of Health web-based training course named "Protecting Human Research Participants" (Certification Number: 2093226). 


\section{Consent for publication}

Not applicable.

\section{Availability of data and materials}

The datasets used and analyzed during the current study are available from the corresponding author in response to reasonable requests.

\section{Competing interests}

The authors declare that they have no competing interests.

\section{Funding}

This study was supported by two Guangdong Provincial science and technology projects (Grant No.201607010186, 201704020153), the Guangdong Provincial Key Laboratory Construction Projection on Organ and Transplant Immunology (Grant NO.2013A061401007), and the Guangdong Provincial International Cooperation Base of Science and Technology (Organ Transplantation) (Grant No. 2015B050501002, 2017B030314018).

\section{Authors' contributions}

XS and ZT participated in the study design, data extraction, statistical analysis, manuscript writing and revision. SL, JX and FH participated in data extraction and statistical analysis. $X H, L T, L C, Y Z, J Y, X L$ and $X G$ helped study design and manuscript revision. $\mathrm{KL}$ and $\mathrm{CC}$ were the guarantors of the content of the manuscript, and took full responsibility for the content of the manuscript, including data and analysis. XS and ZT contributed equally to the article and should be regarded as co-first authors. All authors read and approved the final manuscript.

\section{Acknowledgements}

We appreciate the excellent work of Philips Healthcare and MIT Laboratory for Computational Physiology to build the elCU Collaborative Research Database and make it freely available to clinical researchers.

\section{References}

1. Rivers E, Nguyen B, Havstad S, Ressler J, Muzzin A, Knoblich B, Peterson E, Tomlanovich M. Early goal-directed therapy in the treatment of severe sepsis and septic shock. N Engl J Med. 2001;345(19):1368-77.

2. Dellinger RP, Levy MM, Rhodes A, Annane D, Gerlach H, Opal SM, Sevransky JE, Sprung CL, Douglas IS, Jaeschke R, et al. Surviving Sepsis Campaign: international guidelines for management of severe sepsis and septic shock, 2012. Intensive Care Med. 2013;39(2):165-228. 
3. Berlin DA, Bakker J. Starling curves and central venous pressure. CRIT CARE. 2015;19:55.

4. Gelman S. Venous function and central venous pressure: a physiologic story. ANESTHESIOLOGY. 2008;108(4):735-48.

5. Vellinga NA, Ince C, Boerma EC. Elevated central venous pressure is associated with impairment of microcirculatory blood flow in sepsis: a hypothesis generating post hoc analysis. BMC ANESTHESIOL. 2013;13:17.

6. Wang X, Chen H, Liu D, Zhang Q, Su L. The correlation between CVP-derived parameters and the prognosis of critically ill patients. J CRIT CARE. 2017;40:257-64.

7. Chen CY, Zhou Y, Wang P, Qi EY, Gu WJ. Elevated central venous pressure is associated with increased mortality and acute kidney injury in critically ill patients: a meta-analysis. CRIT CARE. 2020;24(1):80.

8. Wang XT, Yao B, Liu DW, Zhang HM: Central Venous Pressure Dropped Early is Associated with Organ Function and Prognosis in Septic Shock Patients: A Retrospective Observational Study. SHOCK 2015, 44(5):426-430.

9. Boyd JH, Forbes J, Nakada TA, Walley KR, Russell JA. Fluid resuscitation in septic shock: a positive fluid balance and elevated central venous pressure are associated with increased mortality. CRIT CARE MED. 2011;39(2):259-65.

10. Pollard TJ, Johnson A, Raffa JD, Celi LA, Mark RG, Badawi O. The elCU Collaborative Research Database, a freely available multi-center database for critical care research. SCI DATA. 2018;5:180178.

11. Rhodes A, Evans LE, Alhazzani W, Levy MM, Antonelli M, Ferrer R, Kumar A, Sevransky JE, Sprung CL, Nunnally ME, et al. Surviving Sepsis Campaign: International Guidelines for Management of Sepsis and Septic Shock: 2016. Intensive Care Med. 2017;43(3):304-77.

12. Yealy DM, Kellum JA, Huang DT, Barnato AE, Weissfeld LA, Pike F, Terndrup T, Wang HE, Hou PC, LoVecchio F, et al. A randomized trial of protocol-based care for early septic shock. N Engl J Med. 2014;370(18):1683-93.

13. Peake SL, Delaney A, Bailey M, Bellomo R, Cameron PA, Cooper DJ, Higgins AM, Holdgate A, Howe $\mathrm{BD}$, Webb SA, et al. Goal-directed resuscitation for patients with early septic shock. N Engl J Med. 2014;371(16):1496-506.

14. Mouncey PR, Osborn TM, Power GS, Harrison DA, Sadique MZ, Grieve RD, Jahan R, Harvey SE, Bell D, Bion JF, et al. Trial of early, goal-directed resuscitation for septic shock. N Engl J Med. 2015;372(14):1301-11.

15. Marik PE, Cavallazzi R. Does the central venous pressure predict fluid responsiveness? An updated meta-analysis and a plea for some common sense. CRIT CARE MED. 2013;41(7):1774-81.

16. Magder S. Value of CVP: an epidemiological or physiological question? Intensive Care Med. 2016;42(3):458-9.

17. Li DK, Wang XT, Liu DW. Association between elevated central venous pressure and outcomes in critically ill patients. ANN INTENSIVE CARE. 2017;7(1):83. 
18. Johnson AE, Pollard TJ, Shen L, Lehman LW, Feng M, Ghassemi M, Moody B, Szolovits P, Celi LA, Mark RG. MIMIC-III, a freely accessible critical care database. SCI DATA. 2016;3:160035.

\section{Figures}

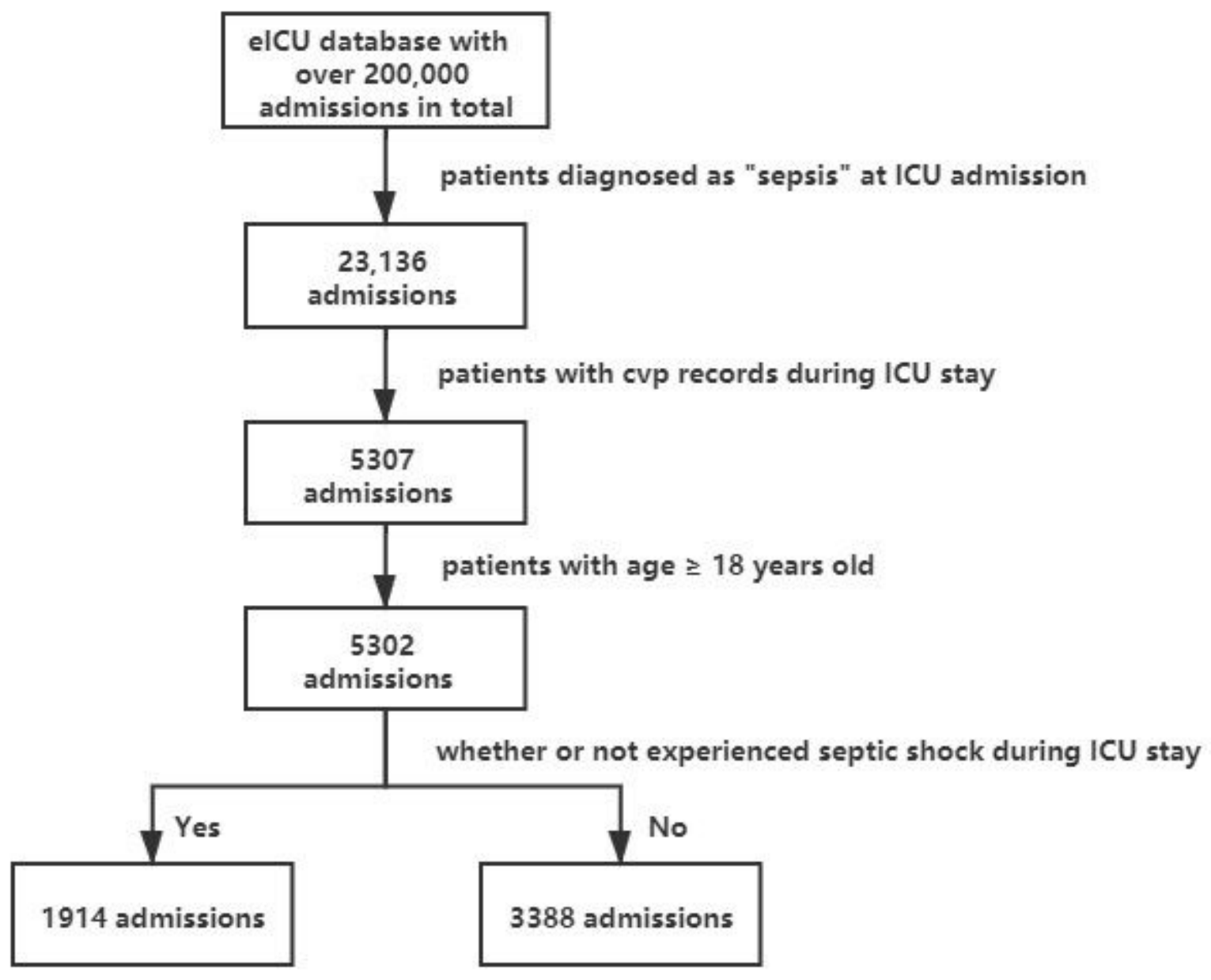

\section{Figure 1}

Flowchart of patient selection in the database. 


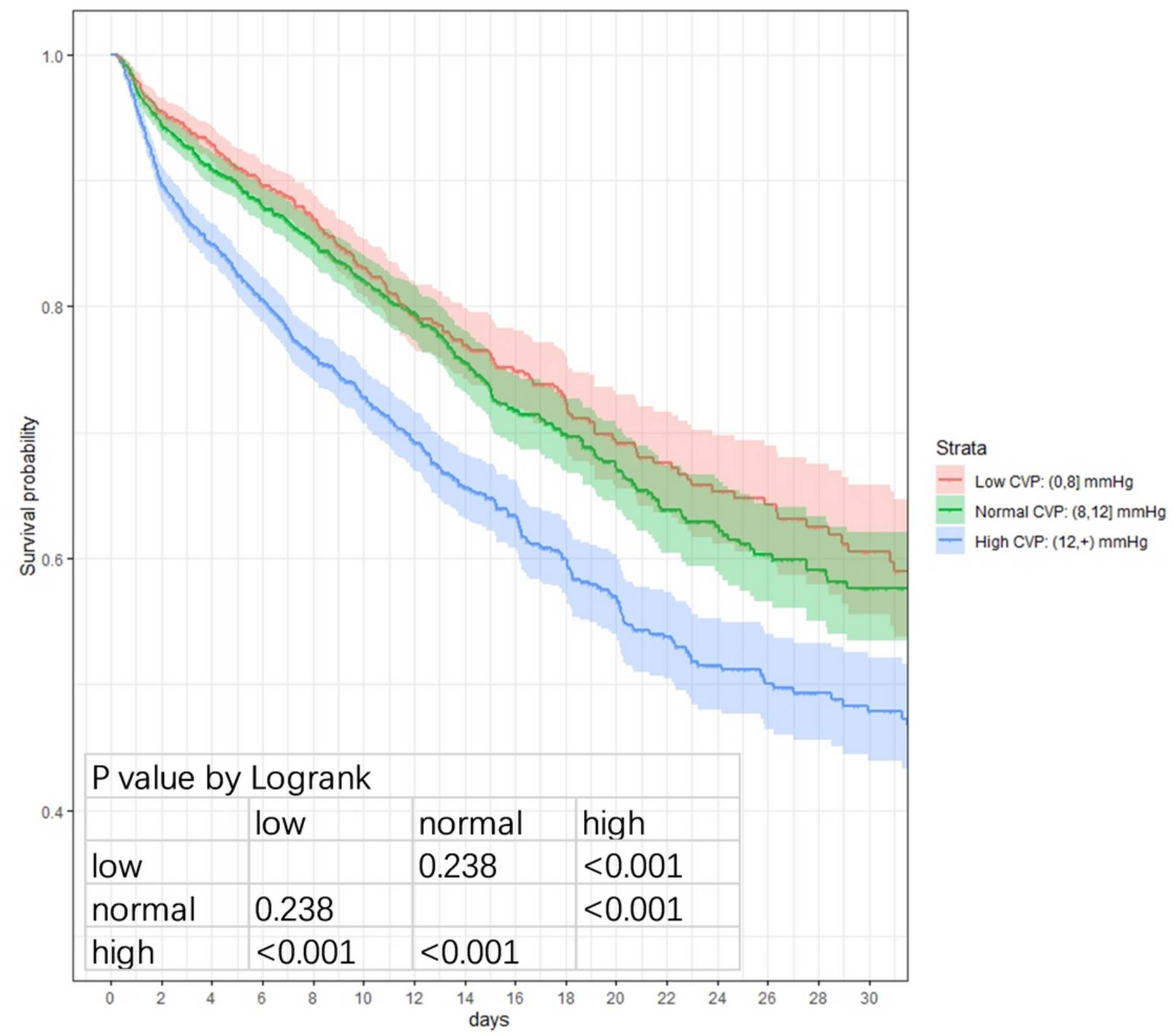

Figure 2

Kaplan-Meier Curve of 30-day survival probability of different CVP group during ICU stay. Corresponding colorful area represent the $95 \%$ confidence interval of each CVP group. (CVP: central venous pressure) 


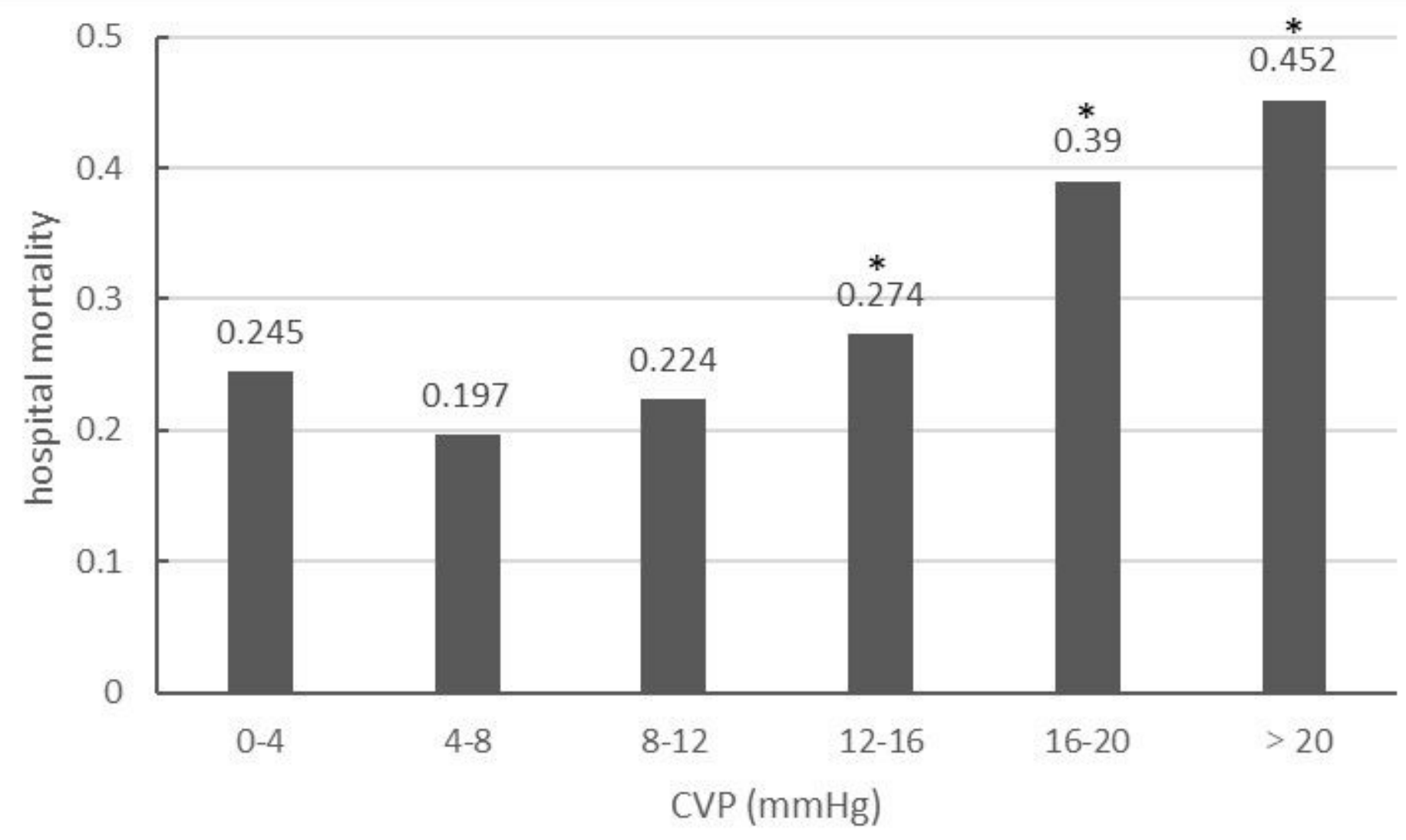

Figure 3

Hospital mortality in sepsis patients grouped by equal interval of $4 \mathrm{mmHg} .{ }^{*}$ means that there is statistically difference between corresponding group and $(8,12] \mathrm{mmHg}$ group. (CVP: central venous pressure) 
variables

apache_iv

age

Diagnosis (Sepsis, cutaneous/soft tissue as reference)

Sepsis, Gl

Sepsis, gynecologic

Sepsis, other/unknown

Sepsis, pulmonary

Sepsis, renal/UTI

gender

septic shock

ventilation

dialysis

vasopressor

antibiotics

hypertension

diabetes

ckd

heartfailure

cancer

CVP (8-12 $\mathrm{mmHg}$ as reference)

$0-4$

4-8

$12-16$

$16-20$

$>20$

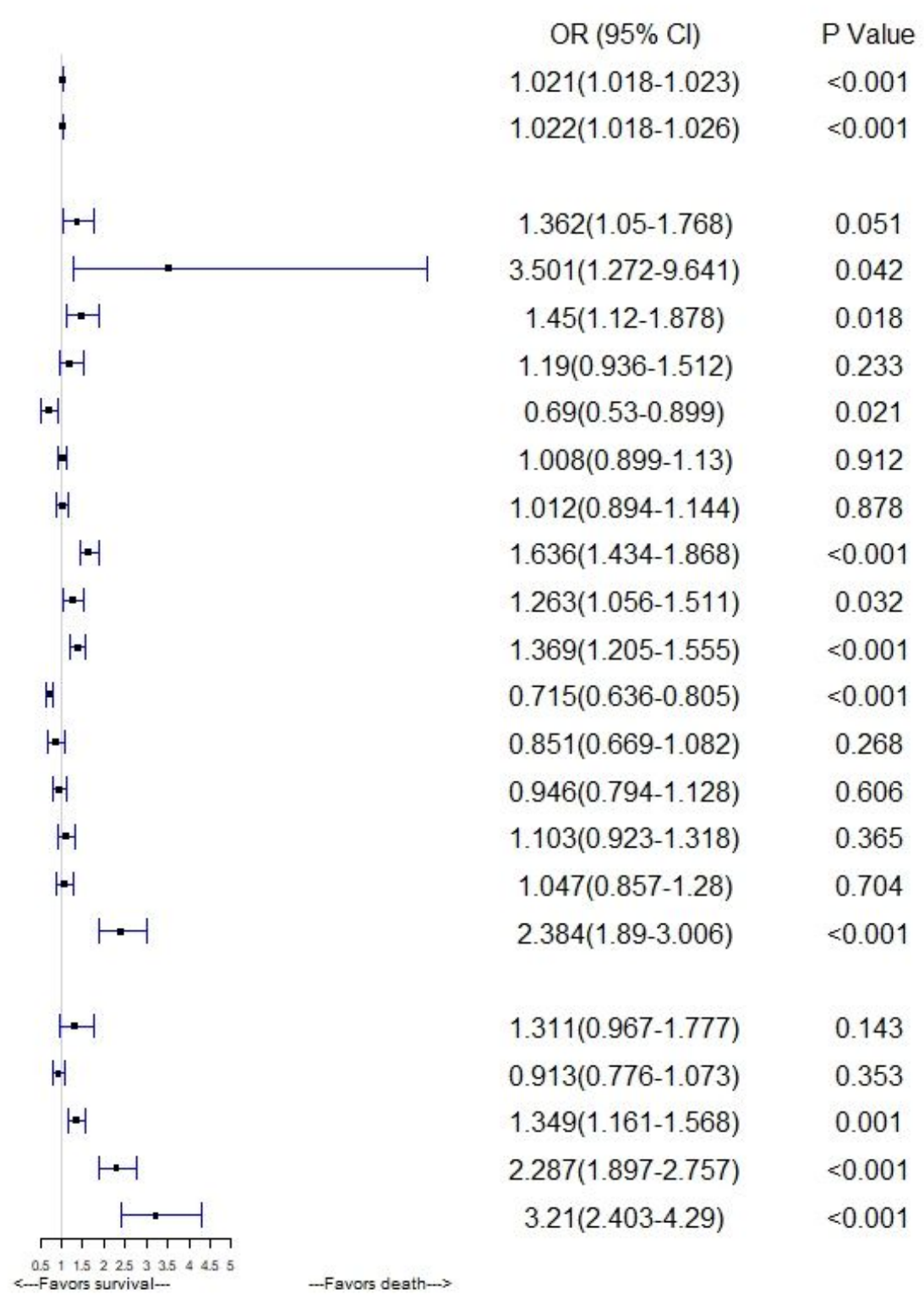

\section{Figure 4}

The multivariate logistics regression model for hospital mortality of sepsis patients. Each horizontal line represents the $95 \% \mathrm{Cl}$ range, and the small black spots in the middle of the crosses represent the OR value. (Apache IV: Acute Physiology and Chronic Health Evaluation IV, UTI: urinary tract infection, CKD: Chronic kidney disease, CVP: central venous pressure)

\section{Supplementary Files}

This is a list of supplementary files associated with this preprint. Click to download.

- SupplementaryMaterial.docx 